\title{
Northeastern United States Census Region
}

National Cancer Institute

\section{Source}

National Cancer Institute. Northeastern United States Census Region. NCI Thesaurus. Code C76329.

A census region of the United States consisting of Maine, New Hampshire, Vermont, Massachusetts, Rhode Island, Connecticut, New York, New Jersey, and Pennsylvania. 